\title{
Effect of Public Transportation on Urban Sprawl in the City of Bhopal, India
}

\author{
Rahul TIWARI, Maulana Azad National Institute of Technology (MANIT), India \\ Utkarsh KAUSHIK, Maulana Azad National Institute of Technology (MANIT), India \\ Lakshman Rao DEVADARU, Maulana Azad National Institute of Technology (MANIT), India
}

\begin{abstract}
Growing urban population has led to recognition of urban sprawl as a serious planning concern, especially in developing countries. Urban economists identify three major responsible forces that interact together and lead to spatial urban sprawl. First, the population growth is resulting in outward expansion of urban areas; second, rising income levels attracting citizens to procure larger living space. These residences are generally located where land prices are less expensive i.e., suburban areas located at the outskirts of metropolitan areas. Interestingly, the third, force responsible for inducing urban sprawl identified in literature is decreasing commuting costs produced by investments in transportation infrastructure which fuel outward expansion of development. Therefore, through review of literature, it is understood that urban sprawl tends to occur where property values are lower on the periphery of urban centres and low-cost public transport availability is one of the major factors that contribute to the sprawling of people from the city centre to the suburbs of the city.
\end{abstract}

Bhopal, the capital city of central state of India implemented bus based public transport facility in year 2005 under National Urban Renewal Mission (NURM) and has till date many folds expanded the service to suburban regions targeting people living there. Notably the municipal area of city has also increased from 265 square kilometres in year 2005 to 463 square kilometres in year 2020. This research study attempts to explain the relationship between public transport expansion and urban sprawl, taking the case study of Bhopal. Spatial data for Bhopal was developed for the years ranging from 2005 to 2020 using ArcGIS and Google Earth Pro, in order to understand the changing city footprint along with details of public transport network over the corresponding period from Bhopal Municipal Corporation (BMC). Standard urban spatial singlemode model to incorporate public subsidies for one mode, i.e., bus based public transport was used. Comparative statistical analysis of model produces empirically testable hypotheses and identified the relation between expansion of city and public transportation available in city by observing the all maps of past to present years of Bhopal. At the end of the research paper, it has been highlighted how public transport expansion impacts urban sprawl by means of the correlation coefficients and spatial analysis. Our most important theoretical result is that the transit subsidies on the suburban areas are directly related to urban sprawl. Arguably, public transport which was targeted as strategy to promote sustainable urban development has resulted in sprawl. The paper ends with a recommendation to examine and analyse the impact of public transport service expansion to sub-urban regions in light of city expansion.

\section{Keywords}

Public, Transportation, Urban, Sprawl 


\section{Introduction}

With increasing population growth and rural to urban migration of population in India, a spike in urban population and urbanisation is unavoidable. This urbanisation has led to increasing urban sprawls, with a change in land uses along the highways and in the near periphery of the cities, hence more and more urban areas are emerging. Urban areas are by definition, dynamic and complex structures that are significant to physical, economic, and population increase which is referred to as urban growth (Aljoufie $M, 2011)$. In the last decade, urban sprawl has served as a strong urban planning concern, with a number of urban problems ascribed to it. It is criticised of consuming an excessive quantity of land in an unregulated manner, resulting in an undesirable division of land uses and services and, as a result, increasing the demand for transport (Sultana S, 2006), because of its quick rising magnitude and the fact that its implications are not always beneficial, urban sprawl is one of the phenomena that require increasing attention from urban planners. This spatial process poses a complicated issue encompassing demographic, economic, environmental, and decisional issues, and it can take several forms depending on the area's characteristics (C. lațu, 2011). A range of factors contribute to urban expansion, including transportation and communication, internal and international migration, public policies, and the globalisation of economic activities. Urbanisation and transportation are inextricably linked challenges. On the one hand, transportation infrastructure encourages urban development; while on the other hand, urban expansion and population increases travel demand, increasing the need for transportation infrastructure and travel costs as well (Aljoufie M, 2011). As a result, understanding transportation and urban dynamics are increasingly becoming a prerequisite for formulating urban development strategies.

Earlier, researches have majorly concentrated on the causes and effects of transportation and urbanisation, with little attention paid to the two's mutual relationship. Hence, this research attempts to answer three interconnected questions or objectives of the aforementioned issue and aims to make a novel contribution to urban development strategies in terms of transportation. First, is there a linkage and correlation between public transportation and urban sprawl, particularly bus-based public transportation in urban areas? Second, how does the city's road layout network affect urban sprawl and population density in any urban agglomeration? Third, using spatial data analysis, can the association or the relationship between the first and second question be analysed or not.

\section{Literature Review}

Since the primary research questions for the study aligned towards the study of linkage between urban sprawl and public transportation and the secondary research question was to understand the impact of public transport network on the urban sprawling process and hence the literature review for this study, focussed mainly these two aspects of urban sprawl and public transport and is detailed subsequently.

\subsection{Urban sprawl expansion and urban mass transport}

Urban sprawl is a worldwide challenge that has altered land usage in both developed and developing countries. Urban sprawl is a complex phenomenon that is influenced by a variety of elements in diverse urban circumstances (Mehriar M, 2020). Mass transit appears to be one of the most important factors to consider. Ineffective growth management in developing countries can lead to urban expansion, which has a severe impact on sustainable mobility. Many researches have shown us that in developing countries, land development management at the state or municipal level faces major problems due to uncertainties regarding controlled development on the urban outskirts, for example, some specific countries such as India and Indonesia (Zhao, 2010). Urban sprawl has been associated with a number of transportation externalities. As the distance among functional urban areas is constantly growing and local municipal corporations are struggling to keep up with the pace of urban expansion, in order to ensure the long- 
term development of transit network and reduce their negative impact on the environment and community (C. lațu, 2011). Arguments have been made that urban sprawl increases commuting times, encourages automobile ownership, increases per capita miles driven, raises automobile accident rates, contribute to air pollution, and increases expenditures on roads that carry the additional traffic sprawl causes (Holcombe R, 2010). As a result, urban expansion is strongly intertwined to urban mass transit network, with reciprocal causes and effects. Causality, reciprocal consequences and causes are all visible aspects of the urban expansion and transportation interaction (Aljoufie M, 2011).

\subsection{Road layout network and urban sprawl}

Over the last few decades, government land use policies have become increasingly oriented toward avoiding the spread of urban sprawl by enacting laws that stimulate urban infill and boost population density in already-developed areas. One of the reasons for advocating more compact urban development is that minimising sprawl can reduce a number of transportation costs by shortening travel durations and encouraging people to adopt alternate means of transportation, which become more practical as population density grows (Holcombe R, 2010). In order to do so, grid road network is promoted, which make heavy use of existing transportation infrastructure. These systems are often centred on the core business district, with few routes venturing far beyond CBD. When traffic is high, such as deep within the $\mathrm{CBD}$, one or more dedicated bus lanes may be required to give buses enough room to move, but these dedicated bus lanes boost system efficiency by decreasing delays caused by intervening traffic, but they also lower the capacity of roadways to handle private traffic and parking (Route and Network Structures, n.d.).

Another one is the radial road network, which are very common in modern cities. These networks provide linear lines from the CBD to the outskirts of the city. Passengers who reside in the suburbs and work in the central business area are well covered by radial networks, but those who require intersuburban transportation are underserved unless direct lines connect each of the suburbs. Exclusive bus lanes are occasionally included on radial routes as well. This network has enough spatial accessibility without losing too much of the average commercial speed, helps to reduce population density but on the other hand increases the travel expenditure of the commuters (Route and Network Structures, n.d.).

\section{Study Area}

Bhopal is the capital city of Madhya Pradesh, a central state of India and is also the administrative headquarters of Bhopal district and Bhopal division, as shown in Figure 1. Bhopal is popularly known as the "City of Lakes" for its various natural as well as artificial lakes and is also one of the greenest cities in India. Bhopal, with its central location is very well connected to all the corners of the country. With the expanded planning area of 463 square kilometres, Bhopal stands among 15 largest cities of India (BMC, 2021).

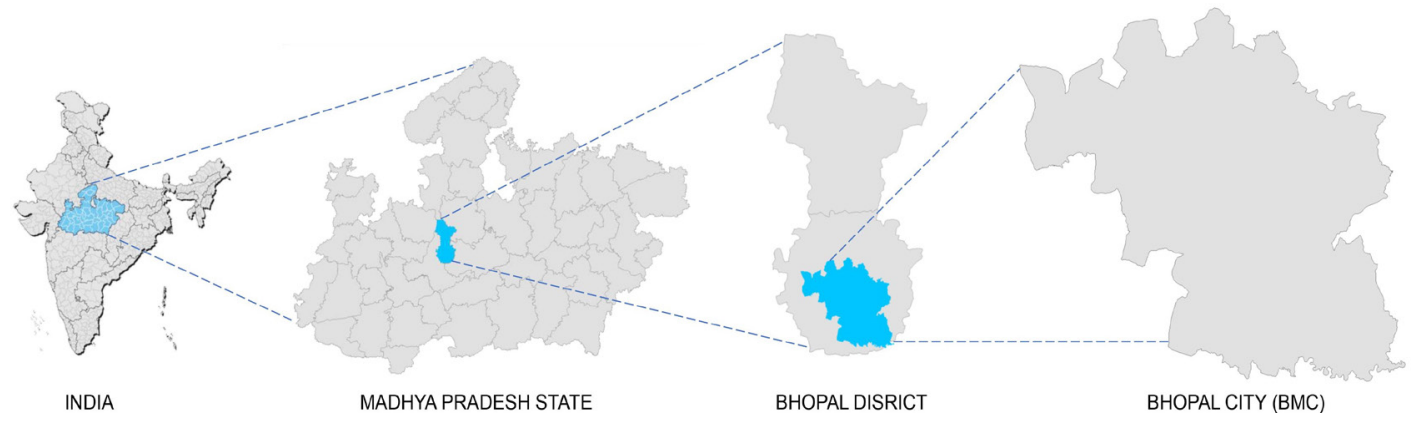

Figure 1: Location map of Bhopal City. Source - Author 


\subsection{BRTS Bhopal}

In past few decades, Bhopal has witnessed major transformation in the subject of urban development per say. Bhopal is known to have one of the successful BRT Systems in the country. The construction of Bhopal BRTS was funded by the Central Government under its flagship Jawaharlal Nehru National Urban Renewal Mission (JnNURM). Unlike most of BRT projects in India which are designed to cater the transportation needs of suburban parts of the city, Bhopal BRTS was designed mainly to serve the Central business districts (CBDs). It started its operation with a fleet of just 30 buses in 2006, after receiving JnNURM sanction, has grown to 225 buses comprising AC and Non-AC low floor buses. Bhopal Bus Operation is one of the successful models in India and has received the UMI National Award in 2011 and 2014 for the "Best practices in PPP initiatives" and Best Urban Mass Transit Project respectively (BCLL, 2021) by Ministry of Housing and Urban Affairs (MoHUA), Government of India.

\subsection{Urban Sprawl Expansion of Bhopal (2005 to 2020)}

Over the years Bhopal city has expanded exponentially since the year 2005 to 2020 and along with that road network has also, grown into intricate routes spread all around the city. Figure 2, illustrates a clear picture of how the city gradually expanded in all the directions but majorly towards the southern part, along with the mix of both grid and radial road network growth, from year 2005 to 2020 .
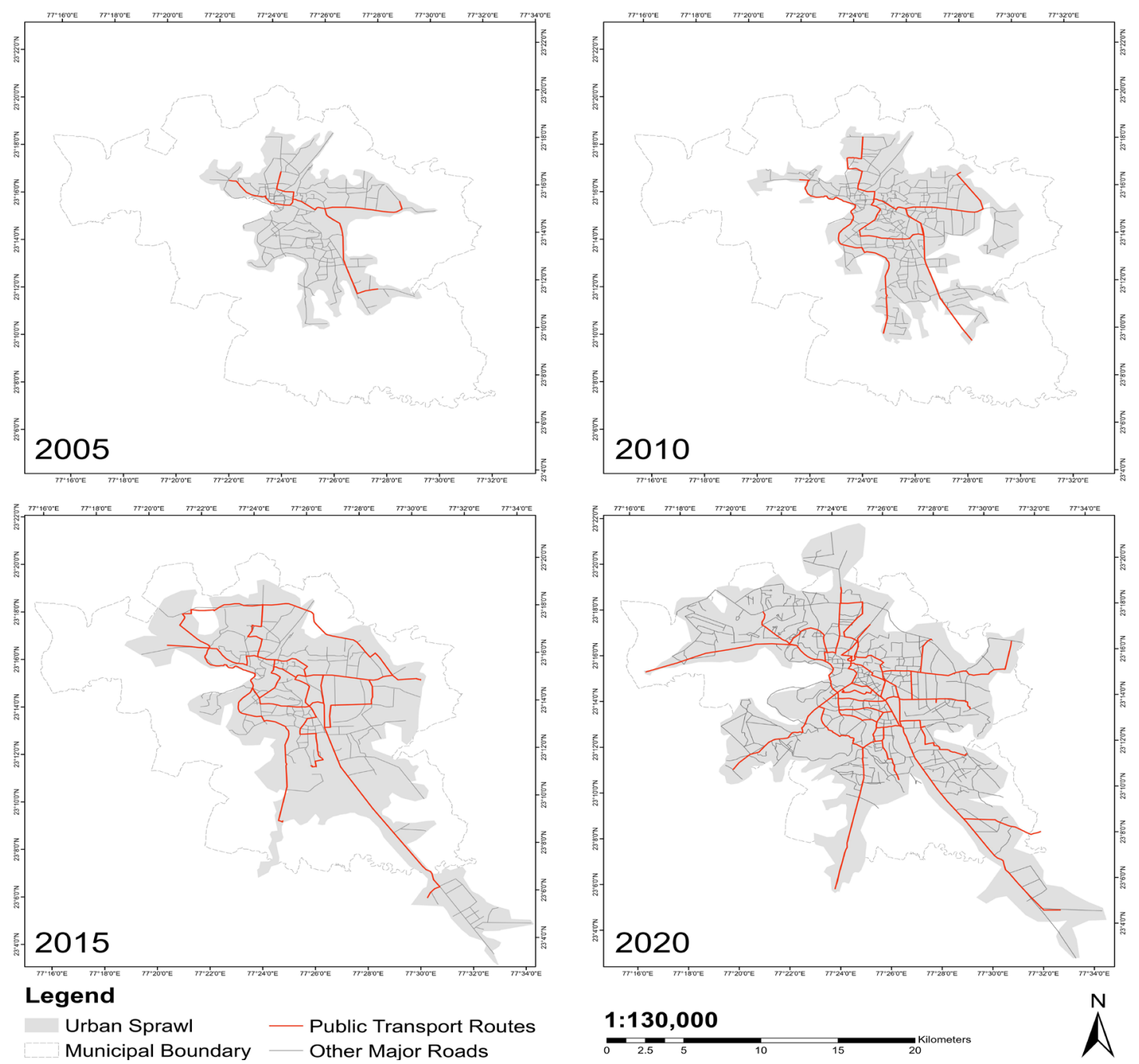

Figure 2. Transport network and urban expansion, over the years (2005 - 2020), of Bhopal. Source: Author 
The heat map, Figure 3, below represents the expansion of urban footprint, for the city of Bhopal, over the period of 15 years i.e., from 2005 to 2020. These maps were prepared by monitoring the city's footprint over the years from Google-earth and ArcGIS.

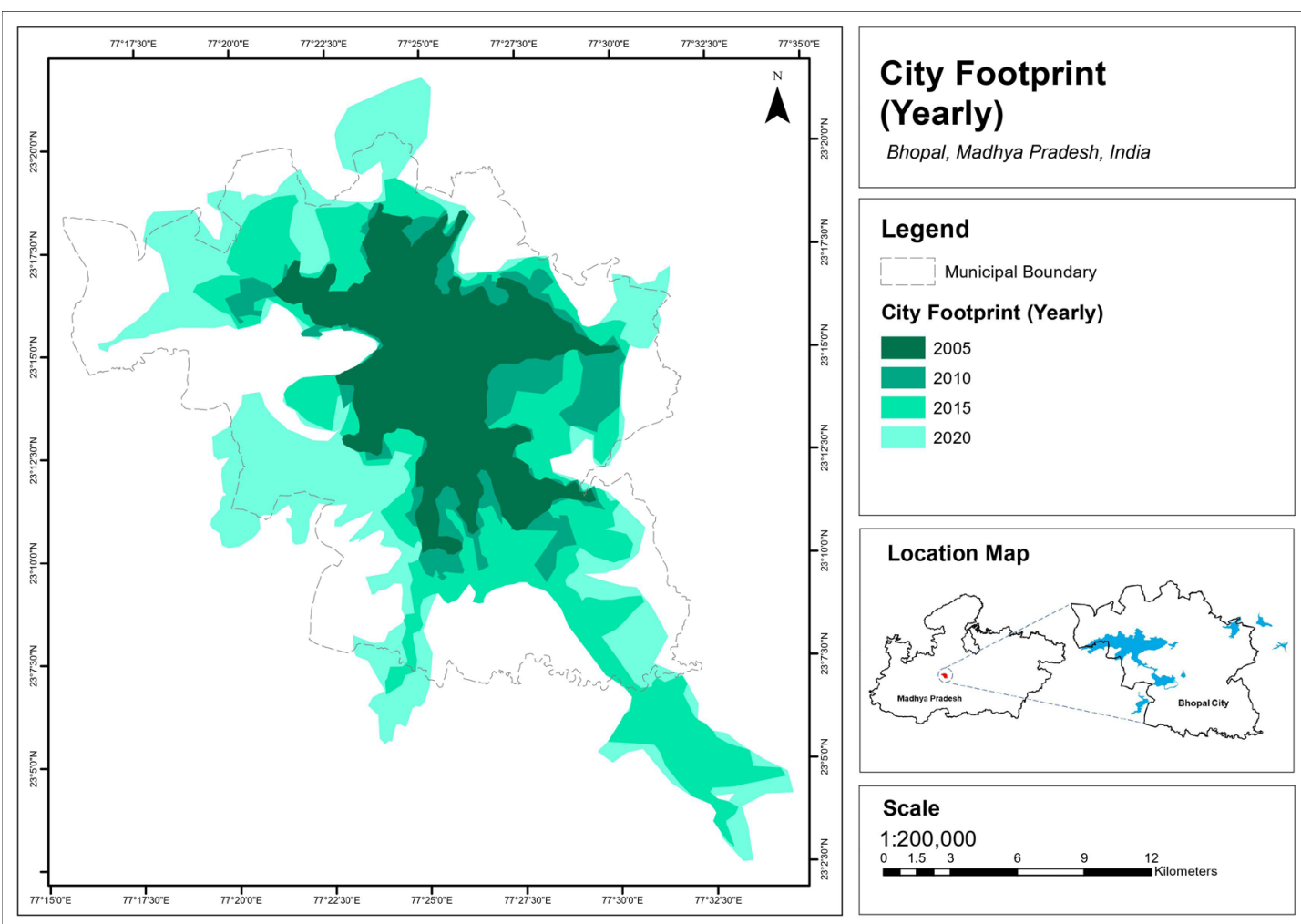

Figure 3: City footprint (Urban expansion), over the years, of Bhopal City. Source - Author

\section{Methodology}

The whole city of Bhopal was divided into 5 urban sprawl expansion zone (USEZ), for micro level analysis of the urban sprawl expansion over the years (2005 - 2020), as shown in Figure 4. These USEZs were named as:

- Central Zone (CZ)

- $\quad$ North - West Zone (NWZ)

- $\quad$ South - West Zone (SWZ)

- $\quad$ South - East Zone (SEZ)

- $\quad$ North - East Zone (NEZ)

The USEZs were divided along the major routes of the city. The CZ belonged to the city center and hence does not show any expansion over the years in terms of urban sprawl, hence will not be included in the analysis, although the numbers of public transport routes have increased. The remaining four zones were named in terms of the directions they were expanding towards. The four zones surround the CZ were split up into year wise urban sprawl, to get a clear idea about the expansion of the urban sprawl from year 2005 to 2020.

The main of objective of the research was to identify the relation between the urban sprawl expansion of the city and its spreading road network. Calculating the correlation coefficient if each urban expansion 
zone could help to achieve the desired results and give the statistical evidences of any liner relationship between the two entities. Hence, Pearson's correlation method was opted to evaluate the relation, by calculating correlation coefficient of each zone, between the expansion of urban sprawl and public transit route.

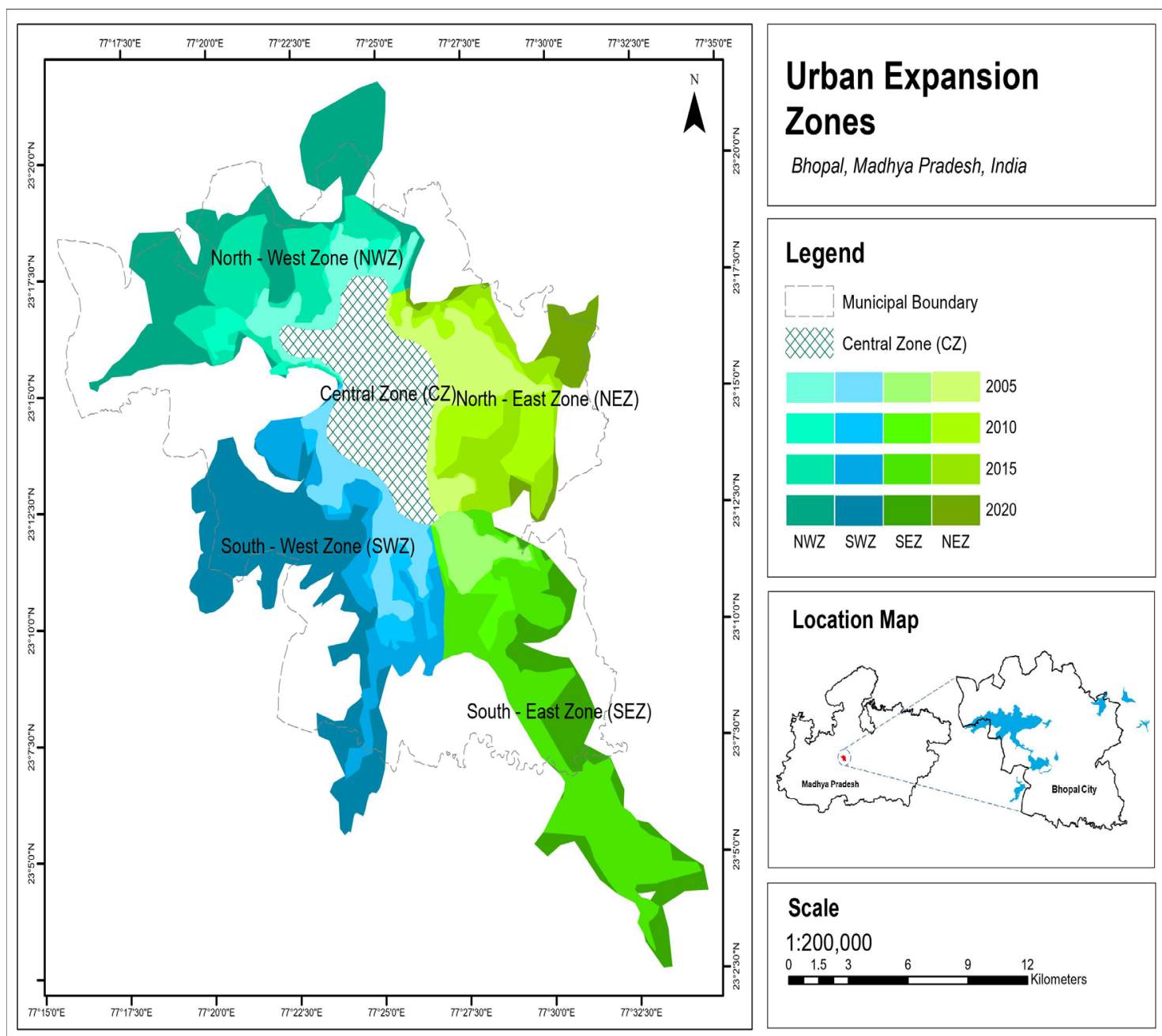

Figure 4: Urban expansion zones of Bhopal City. Source - Authors

\section{Study Analysis}

The study area was sub divided into 5 zones, as detailed before. Since the central zone could not expand, hence was not included in the further analysis. The area of each zone was cumulated over the years from the spatial data. Similarly the public transport route length was derived for the same duration for each of the study zone, separately. In order to check for any association amongst these two variables, i.e. urban sprawl and public transport, the increase in both the variables was converted in terms of percentage increase during tenure of five years. This was necessary for comparison and deriving relationship, as for that the units of variables shall be same in order to develop meaningful insight. The data in square kilometers and route length in kilometers was insufficient to calculate the increment; hence the percentage increase in footprint area and public transport (PT) route was calculated for each USEZ. This percentage increase was calculated for past 15 years (2005 - 2020), with five yearly ranges, is shown in figure Table 1. 
Table 1: Zone wise percentage increase in footprint area and public transport (PT) route.

\begin{tabular}{|c|c|c|c|c|c|c|c|c|}
\hline \multirow{2}{*}{ Years } & \multicolumn{2}{|c|}{$\begin{array}{c}\text { North - West Zone } \\
\text { (NWZ) }\end{array}$} & \multicolumn{2}{|c|}{$\begin{array}{c}\text { South - West Zone } \\
\text { (SWZ) }\end{array}$} & \multicolumn{2}{|c|}{$\begin{array}{c}\text { South - East Zone } \\
\text { (SEZ) }\end{array}$} & \multicolumn{2}{|c|}{$\begin{array}{c}\text { North - East Zone } \\
\text { (NEZ) }\end{array}$} \\
\cline { 2 - 9 } & $\begin{array}{c}\text { \%age } \\
\text { increase } \\
\text { in area }\end{array}$ & $\begin{array}{c}\text { \%age } \\
\text { increase } \\
\text { in PT } \\
\text { route }\end{array}$ & $\begin{array}{c}\text { \%age } \\
\text { increase } \\
\text { in area }\end{array}$ & $\begin{array}{c}\text { \%age } \\
\text { increase } \\
\text { in PT } \\
\text { route }\end{array}$ & $\begin{array}{c}\text { \%age } \\
\text { increase } \\
\text { in area }\end{array}$ & $\begin{array}{c}\text { \%age } \\
\text { increase } \\
\text { in PT } \\
\text { route }\end{array}$ & $\begin{array}{c}\text { \%age } \\
\text { increase } \\
\text { in area }\end{array}$ & $\begin{array}{c}\text { \%age } \\
\text { increase } \\
\text { in PT } \\
\text { route }\end{array}$ \\
\hline $\begin{array}{c}2005- \\
2010\end{array}$ & 26.67 & 87.50 & 30.00 & 100.0 & 30.00 & 50.00 & 47.06 & 20.00 \\
\hline $2010-$ & 61.54 & 65.22 & 51.22 & 26.67 & 81.13 & 60.00 & 32.00 & 56.52 \\
\hline $2015-$ & 51.25 & 4.17 & 52.32 & 59.46 & 23.19 & 42.31 & 12.28 & 17.86 \\
\hline
\end{tabular}

Source: Authors

The tabulated data was to be checked for correlation, and since the data was discrete and continuous, hence Pearson's correlation coefficient was chosen to be applied on the data. Pearson correlation coefficient method was attempted on the data hence received and results of the statistical analysis were obtained, as shown in Table 2. It was found that North West Zone and South West Zone where the public transport routes was expanded in a grid and not radial had negative correlation between the public transport route increase and the urban expansion whereas South East Zone where the public transport route was extended radially has significant positive correlation between public transport route increase and urban expansion, it is interesting to note that maximum positive correlation was seen in the South East Zone (SEZ). These results also justify the second objective of the study that public transport route network type also affects the urban expansion, as it is clear that radial network helped in expanding the growth of the urban sprawl by connecting the outskirts of the city with the city Centre, in South East Zone.

Table 2: Pearson correlation coefficient values calculated for each urban expansion zone.

\begin{tabular}{|l|c|c|}
\hline Urban Expansion Zone & Pearson's Correlation Coefficient & Level of Significance \\
\hline North - West Zone (NWZ) & -0.47 & 0.008 \\
\hline South - West Zone (SWZ) & -0.87 & 0.012 \\
\hline South - East Zone (SEZ) & 0.94 & 0.000 \\
\hline North - East Zone (NEZ) & 0.13 & 0.048 \\
\hline
\end{tabular}

Source: Authors

\section{Discussions and Conclusions}

Results illustrate a strong reciprocal relationship between city footprint increase and public transport routes expansion in Bhopal city, when the public transport network is made denser, thereby increasing the public transport route per unit area high, whereas the strongest positive correlation was seen the South East Zone which also indicates that they are positively correlated with the increasing transport route and urban expansion, this is because of the radial expansion of the public transport route. The analysis also justified the relation between the public transport network pattern and urban sprawl, as the 
radial growth of road network of the Bhopal city has also resulted in the expansion of the urban sprawl. The finding make it clear that public transport when expanded to serve peripheral and outskirts area, tend to have positive impact on the urban sprawl but alternatively when the public transport route are extended to make the network dense, it tend to make the city compact and dense. Hence, the planners and city administrators need to consider this effect of increasing public transport route on urban sprawl while planning the routes and preparing the route rationalization plans for any city.

\section{References}

Aljoufie M, Z. M. (2011). Urban growth and transport: Understanding the spatial temporal relationship. WIT Transactions on the Built Environment, (p. 14).

Andersson, M. (n.d.). Chapter 5 Urban Expansion and Public Transport: Implications for Inclusive Development.

BCLL, B. (2021). About us - Brief overview of BCLL. Retrieved from My Bus Bhopal: https://mybusbhopal.in/about-us/

BMC. (2021). About Bhopal. Retrieved from Bhopal Municipal Corporation: http://www.bhopalmunicipal.com/city-information/about-bhopal.html

C. Iațu, A. M. (2011). The effects of transportation system on the urban sprawl process for the city of lasi, Romania. WIT Transactions on the Built Environment, (p. 11).

Holcombe R, W. D. (2010). Urban Sprawl and Transportation Externalities. The Review of Regional Studies, 16.

Mehriar M, M. H. (2020). Urban sprawl, socioeconomic features, and travel patterns in middle east countries: A case study in Iran. Sustainability (Switzerland), 20.

Reid Ewing, R. P. (2003). URBAN SPRAWL AND TRANSPORTATION. TRB 2003 Annual Meeting CD-ROM, p. 21.

Route and Network Structures. (n.d.). Retrieved from Bus Service Planning: https://www.webpages.uidaho.edu/niatt_labmanual/chapters/busserviceplanning/theoryandco ncepts/RouteAndNetworkStructures.htm

Sultana S, W. J. (2006). Urban Sprawl, Commuting, and Access to Public Transportation in the Southeast Metropolitian Areas. Papers of the Applied Geography Conferences, (p. 11).

Travisi C, C. R. (2010). Impacts of urban sprawl and commuting: a modelling study for Italy. Journal of Transport Geography, 11.

Zhao, P. (2010). Sustainable urban expansion and transportation in a growing megacity: Consequences of urban sprawl for mobility on the urban fringe of Beijing. Habitat International, 8. 